\title{
Use and Evaluation of Computer-Aided Translation Tools (CAT) on the Word Level from the Perspective of Palestinian Translators and Translation Trainees
}

\author{
Imad Abu Dayyeh \\ English Department, Faculty of Arts, Bethlehem University \\ Bethlehem, Palestine
}

\begin{abstract}
This research study aimed to identify the use and evaluation of Computer-Aided Translation (CAT) tools in the translation of Arabic/English words and expressions from the perspective of Palestinian translators and translation trainees (PTTT). Previous studies have addressed technology and translation in general and the use of CAT tools in particular, still there have been no studies that addressed the evaluation of Arabic- English CAT tools. A sample of 400 translators and translation trainees were selected, and a questionnaire, adapted from a Chinese study (Xu \& Wang 2011), was completed by 308 participants. In addition, 12 semi-formal interviews were conducted with selected PTTT. Results revealed that PTTT highly recommended using CAT tools, indicating that they are fast and convenient; still the majority considered them unreliable and recommended that caution should be practiced in using them. Not all CAT tools are used by PTTT, either because they are new or not sufficiently developed to handle some of the challenges of parsing and translating Arabic.
\end{abstract}

Keywords: Authoritative websites, Computer-Aided Tools, Online Dictionaries, Palestinian translators, Translation Trainees, Search Engine

Cite as: Abu Dayyeh, I. (2020). Use and Evaluation of Computer-Aided Translation Tools (CAT) on the Word Level from the Perspective of Palestinian Translators and Translation Trainees. Arab World English Journal for Translation \& Literary Studies 4 (1) 111-130. DOI: http://dx.doi.org/10.24093/awejtls/vol4no1.9 